\title{
REMOVAL OF DISSOLVED GASES FROM LIQUIDS BY VACUUM SUBLIMATION
}

\author{
By James H. Hibben
}

ABSTRACT

A method of removing and collecting dissolved gases from liquids is described. It is possible, through the application of the principle of vacuum sublimation, to prepare gas-free liquids for use in the determination of physical constants without appreciable loss of either liquid or dissolved gas. Experimental results are presented which demonstrate the practicability of the method as well as its theoretical limitations.

\section{CONTENTS}

I. Introduction

II. Theory _... 98

III. Description of apparatus.

IV. Method of operation 100

V. Experimental results _...

1. Purification of water, Part I, $\mathrm{HN}_{3}$ as the impurity _...... 101

2. Purification of water, Part II, $\mathrm{HCl}$ as the impurity _...... 102

3. Purification of water, Part III, $\mathrm{O}_{2}$ as the impurity

4. Purification of water, Part IV, $\mathrm{CO}_{2}$ as the impurity ..... 103

VI. Summary

104

\section{INTRODUCTION}

The complete removal of dissolved gas from a liquid is usually the final step in the purification of the liquid for the purpose of determining certain of its physical properties. Removal by chemical means is often impracticable, particularly in the case of the gases of the atmosphere. The collection of the dissolved gas for analytical purposes is also of importance, for example, in determinations of gas solubilities. The general physical method of purification described below not only permits the complete removal of the dissolved gas, in most cases, but also allows an approximately complete recovery of both the gas and liquid.

The various methods described in the literature fall into four categories-those employing vacuum, ${ }^{1}$ those employing heat, ${ }^{2}$ those

1 Frankland, J. Chem. Soc., 6, p. 109; 1854. Meyer, Z. anal. Chem., 2, p. 237; 1863. Swanson and Hulett J. Am. Chem. Soc., 37, p. 2s90; 1915. Jones, Yant, and Buston, Bureau of Mines Reports of Investigations No. 2553; December, 1923. McClendon, J. Biol. Chem., 30, p. 259; 1927. Van Slyke, J. Biol. Chem., 30, p. 347; 1917; 49, p. 44; 1921. Austin and others, J. Biol. Chem., 54, p. 129; 1922. Hall, J. Biol. Chem., 55, p. 751; 1923.

2 Reichardt, Z. anal. Chem., 11, p. 271; 1872. Jacobsen, Ann., 167, p. 12; 1873. Petterson, Ber., 22, p. $1434 ; 1889$. 
employing both vacuum and heat, ${ }^{3}$ and those employing freezing. ${ }^{4}$

Unfortunately little information is available as to the relative effectiveness of these processes. Heating alone does not prevent the resolution of the atmospheric gases on cooling, unless special precautions are taken, and it results in a partial loss of the liquid. Evacuation alone involves a similar loss of liquid, and only a partial removal of the total gas content if a constant boiling mixture is formed. Heating combined with evacuation is more effective, although the manipulation is generally inconvenient. The vacuum attainable is limited by the vapor pressure of the liquid at the temperature of condensation, so that the rate of removal is low. There is some loss of liquid, and a constant boiling mixture can not be completely freed from gas. Freezing, alone, is somewhat effective only in the removal of the permanent gases.

The vacuum sublimation process, to be described, includes all the processes named above, since it employs heat, vacuum, and freezing.

The liquids to be freed from gas are vaporized and frozen in vacuo. While the use of vacuum sublimation ${ }^{5}$ as a possible means of purification is not new ${ }^{6}$ there are certain experimental requirements which must be met, otherwise little purification will result. These have not been heretofore discussed.

\section{THEORY}

The conditions essential to the best operation of the process of purification by vacuum sublimation are as follows: (a) The temperature at the condensing surface must be considerably below the freezing point of the pure liquid so that its vapor condenses directly to a solid, otherwise a resolution of the gas impurity may occur if a liquid phase is present at the condensing surface during condensation. (b) The sublimate must have a negligible vapor pressure at the temperature of condensation or a loss of the pure material will result. (c) The third condition can be stated in the following general form: The vapor pressure of the impurity from any system containing it which can exist on the condenser must be greater than the partial

\footnotetext{
${ }^{3}$ McLeod, J. Chem. Soc., 7, D. 313; 1855. Hamberg, J. prakt. Chem., 141, p. 433, 1885. Hoppe-Seyler, Z. anal. Chem., 31, p. 367; 1892. Thresh, Trans. Chem. Soc., 39, p. 399; 1881. Thomas, Chem. News, 36, p. 37; 1877. Thorner, Chem. Zentr., 16, p. 129; 1877. Richardson, J. Soc. Chem. Ind., 29, p.198T; 1910; 38, p. 32T; 1919. Lorah, Williams, and Thompson, J. Am. Chcm. Soc., 49, p. 2991; 1927. Many patents have been granted for commercial degassing processes, utilizing one or more of these methods.

- Faraday, Researches in Chemistry and Physics, Taylor and Francis, p. 373; 1859. It is interesting to note that Mark Twain in "Life on the Mississippi," Author's National Edition, Iarper \& Bros., p. 303, mentions the removal of dissolved air hy stirring during the freezing process in the manufacture of ice at New Orleans.

5 The term suhlimation as used in this article may bc defined as the process of passing directly from the vapor to the solid statc of aggregation, and is therefore independent of whether the suhstance sublimed was originally in the liquid or solid state.

${ }^{6}$ McKelvy and Taylor, B. S. Sci. Pupers, 18, p. 679; 1923, Gray, J, Chem, Soc., 87, p. 1606; 1905.
} 
pressure of the impurity in the gas phase. The following are possible systems of this kind: (1) A liquid phase in equilibrium with the sublimate. Such a system can form only above the eutectic temperature and for a given condenser temperature only if the partial pressure of the impurity in the gas phase exceeds a certain fixed value characteristic of the system. (2) The solid impurity. (3) Mixed crystals containing both sublimate and impurity. (4) Adsorbed impurity.

Condition $(c(4))$ can never be realized since for every pressure of the impurity in the gas phase some adsorption on the condensate is possible. This difficulty is usually of secondary importance, however, and its effect can be made as small as desired by repeated sublimations. The contamination resulting from $(c(3))$ is likewise reduced by successive sublimations.

The partial pressure of the impurity in the gas phase may be reduced by continuous pumping. The limiting total pressure thus obtainable is the vapor pressure of the sublimate. For example, with water as the liquid to be purified, $\mathrm{NH}_{3}$ as the impurity, and a condensation temperature of $-78^{\circ} \mathrm{C}$., the minimum total pressure obtainable is $0.001 \mathrm{~mm} \mathrm{Hg}$. The partial pressure of $\mathrm{NH}_{3}$ from its aqueous solution in equilibrium with ice at this temperature is of the order of a millimeter. Condition $(c(1))$, therefore, can not occur and purification results. Similarly with $\mathrm{CO}_{2}$ and $\mathrm{O}_{2}$ as impurities, the water may be completely freed from gas.

A different circumstance is met, however, if $\mathrm{HCl}$ is the impurity. The partial vapor pressure of $\mathrm{HCl}$ from its aqueous solution in equilibrium with ice at $-78^{\circ} \mathrm{C}$., is much less than $0.001 \mathrm{~mm} \mathrm{Hg}$, and condition $(c(1))$ may occur. Part of the ice melts and a resolution of $\mathrm{HCl}$ occurs.

In the experiments to be described, $\mathrm{NH}_{3}, \mathrm{HCl}, \mathrm{CO}_{2}$, and $\mathrm{O}_{2}$ were chosen as gas impurities. For the most part water could, of course, be conveniently freed from these particular impurities by chemical means. They represent, however, types of gas impurities, the complete elimination of which has been heretofore, difficult by physical means.

\section{DESCRIPTION OF APPARATUS}

The final form ${ }^{7}$ of the apparatus employed is shown in Figure 1.

The apparatus consisted essentially of sublimation vessel $A$, liquid air trap $E$, McLeod gage $F$, mercury vapor pump $G, \mathrm{P}_{2} \mathrm{O}_{5}$ drying tubes $H$, and an oil pump. The sublimation vessel $A$ was a modified Dewar tube. While the exact dimensions are not essential, it is necessary that the inside tube $C$ be of sufficient length, and the space between the two tubes sufficiently small, to condense all the vapor. The distance between the surface of the sample at $D$ and the bottom

7 Other forms were tried and rejected on account of inadequate cooling or too slow a sublimation. 
of the tube $C$ must be sufficient to prevent small particles of the sample being carried to $C$ when evaporation is rapid, but not so great as to materially retard the sublimation. For larger quantities. of liquid the dimensions may be suitably increased.

The apparatus may be easily modified so that the purified liquid may be distilled in vacuo directly into a conductivity cell or other apparatus. If it is desired to collect the dissolved gases, a Töpler pump may be employed.

\section{METHOD OF OPERATION}

From 10 to $25 \mathrm{ml}$ of the liquid to be freed from gas is introduced into the sublimation tube by means of a pipette lowered through the

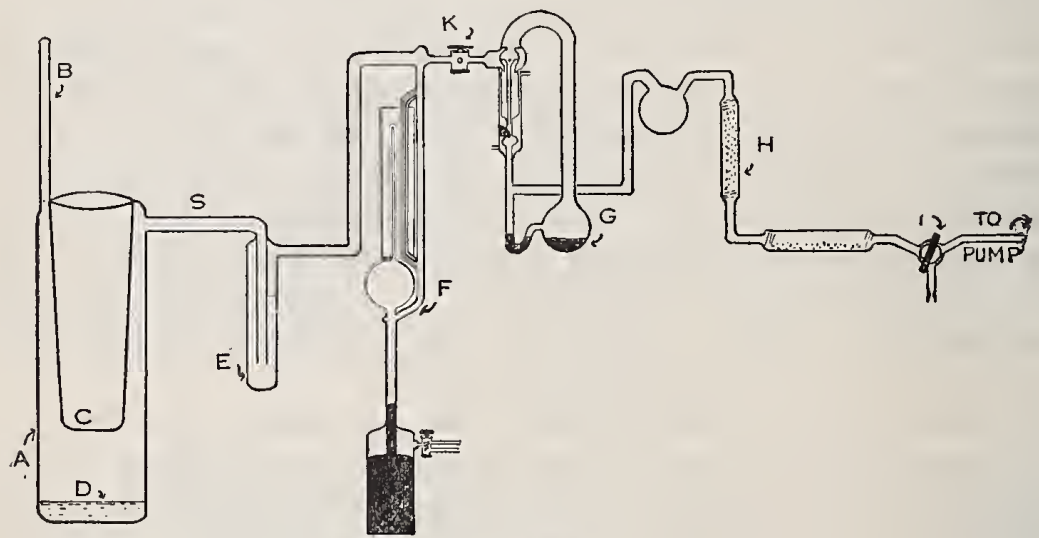

Figure 1

side arm $B$. Care is taken to allow no drops from the end of the pipette to touch the walls of either the inside or outside tubes. The side arm is then sealed off at the top. The entire apparatus is subsequently evacuated until the pressure is somewhat above that of the vapor pressure of the liquid to be purified. A cooling agent is then introduced into tube $C$.

If the temperature gradient between the liquid at $D$ and tube $C$ is great, and the vapor pressure of the liquid relatively high, the rate of evaporation will be excessive, and some of the impure liquid will be carried up in the vapor stream. The temperature, and, consequently, the vapor pressure, of the liquid must be adjusted by means of a suitable bath so that sublimation takes place at a reasonable rate. In the case of liquids of high vapor pressure, it is necessary to freeze them. After the temperatures of the liquid and of the condensing tube are correctly adjusted, the evacuating pumps are started and run continuously. In actual practice with water as the impure liquid; for example, the temperature of condensation is maintained 
at about $-78^{\circ} \mathrm{C}$. by means of $\mathrm{CO}_{2}-$ snow and ether. The vapor pressure of water at this temperature is $0.001 \mathrm{~mm}$. No significant loss occurs. The water is initially cooled with an ice pack and the reduction in pressure carried out very slowly. Because of the cooling effect from the vaporization, the water in $D$ rapidly freezes. The rate of sublimation is so rapid, even under these conditions, that the ice is rapidly cooled. It is necessary, then, to warm the ice by a water jacket. This jacket may be maintained at a temperature between $50^{\circ}$ and $80^{\circ} \mathrm{C}$. without melting the ice. Without this external heat the sublimation is too slow.

When the sublimation is complete, the tube $C$ is warmed, and the sublimate melts and drops to the bottom. The apparatus is still kept evacuated during this process. The liquid on the bottom is then frozen and cooled so that any traces of liquid remaining on the tube $C$ distill to the bottom. A stopcock may be introduced at $S$ between the sublimation tube and the mercury trap to prevent the distillation of the water into the trap during this operation. The process of sublimation may then be repeated if necessary. In case the impurity to be removed is other than the atmospheric gases, the stopcock may be omitted and the apparatus filled with purified air during the melting process.

\section{EXPERIMENTAL RESULTS}

\section{PURIFICATION OF WATER, PART I, AMMONIA AS THE IMPURITY}

Experiment 1.-The results of experiment 1 are given in the following table:

TABLE 1.-Change in ammonia concentration with sublimation

\begin{tabular}{|c|c|}
\hline $\begin{array}{c}\text { Number of } \\
\text { sublimations }\end{array}$ & $\begin{array}{c}\text { Ammonia } \\
\text { concentra- } \\
\text { tion (in } \\
\text { mg per ml) }\end{array}$ \\
\hline 0 & 1.1 \\
$1-\cdots$ & 0 \\
$2-0 .---16$ \\
$3-0075$ \\
\hline
\end{tabular}

The $\mathrm{NH}_{3}$ concentration was estimated colorimetrically by means of Nessler's reagent. The temperature of condensation was approximately $-78^{\circ} \mathrm{C}$.

Only three-quarters of the original sample of $20 \mathrm{ml}$ was sublimed in the last case. The residue was tested for $\mathrm{NH}_{3}$ and showed an increase from 0.025 to $0.040 \mathrm{mg} \mathrm{NH}$ per ml-that is, a total of 0.07 $\mathrm{mg}$ of the $\mathrm{NH}_{3}$ in the residue was present as the carbonate. After the second sublimation the actual free $\mathrm{NH}_{3}$ was, therefore, $0.021 \mathrm{mg}$ 
per ml. The residual $\mathrm{NH}_{3}$ after several sublimations would approach $0.0036 \mathrm{mg} \mathrm{NH} \mathrm{NH}_{3}$ per $\mathrm{ml}$. By sublimation of the greater fraction and rejection of the small remaining residue the ultimate limit of purification would be considerably extended.

EXPERIMENT II.-This experiment was unaertaken to compare the relative effectiveness of freezing alone as compared with freezing followed by sublimation. The $25 \mathrm{ml}$ sample was frozen in vacuum with pumping, as in the preceding experiments. After two freezings the initial ammonia concentration of $1.0 \mathrm{mg}$ per $\mathrm{ml}$ was reduced to $0.5 \mathrm{mg}$ per $\mathrm{ml}$. With two more freezings this became $0.30 \mathrm{mg}$ per $\mathrm{ml}$.

Between the second and third freezings enough $\mathrm{NaOH}$ was added to correspond to about one-half of the $\mathrm{NH}_{3}$ left. This was to fix the $\mathrm{CO}_{2}$ possibly present. Following the fourth freezing the solution was sublimed as in the preceding experiments. The first sublimation gave immediately a change from 0.3 to $0.05 \mathrm{mg}$ per $\mathrm{ml}$.

The efficiency of the sublimation process is much greater than that of the freezing alone in this case.

\section{PURIFICATION OF WATER, PART II, HYDROCHLORIC ACID AS THE IMPURITY}

The method devised for the purification of the water-ammonia solution was then applied to dilute solutions of $\mathrm{HCl}$. The concentration of the acid was determined in the following manner: $1 \mathrm{ml}$ of the $\mathrm{HCl}$ solution of unknown concentration was added to $7 \mathrm{ml}$ of saturated potassium iodate solution containing $30 \mathrm{~g}$ of $\mathrm{KI}$ in $200 \mathrm{ml}$. To this five drops of starch solution were added. The iodine, freed by the reaction of $\mathrm{HCl}$ with $\mathrm{KIO}_{3}$, colors the starch in the usual manner. This colored solution was then colorimetrically compared with a solution which had been treated with a known amount of $\mathrm{HCl}$.

The sublimation procedure was the same as that previously described.

In the first experiment the concentration of $\mathrm{HCl}$ changed from 1.0 to $0.95 \mathrm{mg}$ per $\mathrm{ml}$ after one sublimation. A second sublimation reduced the concentration only to $0.70 \mathrm{mg}$ per $\mathrm{ml}$. The volume of the sample was $25 \mathrm{ml}$.

In a second experiment the $\mathrm{HCl}$ concentration in $\mathrm{mg}$ per $\mathrm{ml}$ changed from 1.0 to 0.90 after one sublimation. In this case $23 \mathrm{ml}$ was sublimed. The remaining $2 \mathrm{ml}$ was withdrawn and titrated with $\mathrm{AgNO}_{3}$ solution. The concentration was slightly less than $2.5 \mathrm{mg}$ per $\mathrm{ml}$. The decrease in concentration caused by sublimation is offset by an increase in $\mathrm{HCl}$ concentration in the residue.

In a third experiment the $\mathrm{HCl}$ concentration changed from 1.0 to $0.88 \mathrm{mg}$ per $\mathrm{ml}$ after one sublimation. The sample was $10 \mathrm{ml}$. All but $4 \mathrm{ml}$ was sublimed. The residue contained $1.25 \mathrm{mg}$ per $\mathrm{ml}$. As in the second experiment, therefore, the decrease in concentration of $\mathrm{HCl}$ in the sublimate is accompanied by an increase in concentra- 
tion of $\mathrm{HCl}$ in the residue. There is no actual removal of $\mathrm{HCl}$ in the process. The $\mathrm{HCl}$ concentration could be diminished by repeated fractional sublimation in this manner. It is evident that condition (c) 1)) under theory occurs.

\section{PURIFICATION OF WATER, PART III, OXYGEN AS THE IMPURITY}

The apparatus used in this case was similar to that used for the purification of water from ammonia or $\mathrm{HCl}$, with the modification that a McLeod gauge was installed in the evacuating system. The oxygen-saturated water was placed in the sublimation system and there frozen during constant evacuation. The system was then closed off from the evacuating pumps leaving the gauge connected to the sublimation apparatus. The ice was then sublimed. During this process the pressure was measured at intervals. From the final pressure and the volume of the system, the residual oxygen at NTP may be calculated. Liquid air was used as the cooling agent in this experiment.

In the first experiment the oxygen concentration was $1.0 \mathrm{ml}$ per $\mathrm{ml}$ in a sample of $25 \mathrm{ml}$. After one freezing, with no purification by sublimation, the oxygen concentration became $0.00048 \mathrm{ml}$ per $\mathrm{ml}$.

\section{PURIFICATION OF WATER, PART IV, CARBON DIOXIDE AS THE IMPURITY}

EXPERIMENT 1.-The $\mathrm{CO}_{2}$ saturated water was treated in precisely the same manner as in the oxygen experiment. $\mathrm{CO}_{2}-$ snow, however, was used as the cooling agent. The saturated solution was evacuated while freezing. Pumping extended over a period of about 15 minutes to remove all the gas liberated from the freezing process alone. The system was then closed and the ice sublimed. The results are given in Table 2 :

$\mathrm{T}_{\triangle \mathrm{BLE}}$ 2.-The amount of carbon dioxide evolved on sublimation after one freezing

\begin{tabular}{|c|c|}
\hline $\begin{array}{c}\text { Duration of } \\
\text { sublimation } \\
\text { (in minutes) }\end{array}$ & $\begin{array}{c}\text { Pressure } \\
\text { of } \mathrm{CO}_{2} \text { in } \\
\mathrm{mm} \mathrm{Hg}\end{array}$ \\
\hline 0 & $\begin{array}{c}0.001 \\
.01 \\
1005\end{array}$ \\
\hline 165 & .163 \\
& .170 \\
\hline
\end{tabular}

The original sample of $25 \mathrm{ml}$ contained $22.5 \mathrm{ml} \mathrm{CO}$ (NTP) per $\mathrm{ml}$ liquid. The final pressure of $0.170 \mathrm{~mm} \mathrm{Hg}$ obtained after sublimation corresponded to a concentration of $0.135 \mathrm{ml} \mathrm{CO}$ per $\mathrm{ml}$ liquid or a reduction to 0.6 per cent of the original concentration by one freezing.

The foregoing data under Parts III and IV represent the degree of purification due to freezing alone. If, however, the process of evacu- 
ation is maintained during the initial sublimation, then after a second sublimation without evacuation the partial pressure of the dissolved gases remaining is not measureable even when the total volume of the system is reduced to $100 \mathrm{ml}$. Within the sensitivity of the pressure-measuring device, this means, for example, that the concentration of oxygen may be reduced by only one sublimation to less than one ten-thousandth of 1 per cent.

The author wishes to express his appreciation of the advice and criticisms given during this research by Dr. E. W. Washburn, and his indebtedness to him for the suggestion of this problem.

\section{SUMMARY}

A method of removing dissolved gases from liquids has been devised which permits the complete recovery of both the dissolved gas and the liquid. Gas-free liquids may be prepared by this method for use in the determination of those physical constants of the liquids wherein extreme purity is prerequisite.

The theoretical and experimental limitations of the system have been discussed.

Washington, September 21, 1928. 